\title{
Una mirada desde Washington: James G. Blaine y el istmo centroamericano (1881-1882)
}

Mónica Toussaint INSTITUTO MORA

\begin{abstract}
Durante su primera gestión, el secretario de Estado James G. Blaine manifestó una preocupación fundamental por proteger los intereses de su país en el istmo centroamericano. De aquí que desarrollara una política exterior activa que buscaba mantener la hegemonía estadunidense en la discusión y solución de los principales problemas regionales.
\end{abstract}

\section{INTRODUCCIÓN}

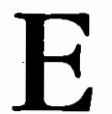
1 interés histórico de Estados Unidos en Centroamérica se explica por la importancia estratégica del istmo, derivada de su posición geográfica en el continente. De ahí su creciente preocupación por evitar cualquier problema en el área que pusiera en juego la estabilidad regional.

Al inicio de la década de los ochenta del siglo XIX, y a raíz del conflicto de límites mexicano-guatemalteco, el secretario de Estado estadunidense, James G. Blaine, ante la perspectiva de un nuevo intento de unión centroamericana, expresó la simpatía de Estados Unidos por ver a los países del istmo fuertemente unidos para defenderse unos a otros.

Blaine veía además, la cooperación de México como indispensable para garantizar la unión y fortaleza de las repúblicas de Centroamérica, al mismo tiempo que consideraba que si el gobierno mexicano no resolvía pacíficamente la cuestión limítrofe y optaba por absorber parte del territorio de América Central, estaría actuando de manera contraria a los intereses continentales. 
Dicha postura correspondía a su visión de la política exterior estadunidense que, para él, tenía dos objetivos ligados entre sí: el primero, favorecer la paz y el segundo, cultivar las relaciones comerciales amistosas con todos los países de América. Desde su punto de vista, la paz duradera sólo podía alcanzarse por medio de un plan concertado por todos ellos, y el problema de límites entre México y Guatemala se había convertido en un obstáculo para lograrlo. Por eso, el arbitraje era un principio de política exterior que debía ser adoptado como un camino para alcanzar la paz. Además, en opinión de Blaine, la unión centroamericana contribuiría en el futuro a la consolidación de las relaciones comerciales de Estados Unidos con la región.

Así, más allá de la tradicional preocupación estadunidense por la construcción de un canal interoceánico en Centroamérica, la política exterior impulsada por el Departamento de Estado a principios de 1880 , se caracterizó por el interés en evitar los conflictos interregionales y por el deseo de sentar las bases para la expansión comercial de Estados Unidos en el continente. Desde esta perspectiva geoeconómica, la posición estratégica de América Central era también fundamental.

Tres fueron los ejes que guiaron la política exterior de Blaine con respecto a América Central: el conflicto de límites con México, la campaña de unión centroamericana encabezada por Justo Rufino Barrios y la discusión sobre la modificación del Tratado Clayton-Bulwer. A cada uno de ellos, dedicaremos un apartado en este trabajo. Pero antes, haremos una breve semblanza de este secretario de Estado que marcó una profunda huella no sólo en la historia estadunidense, sino también en la de los países de América Latina.

\section{BLAINE DE MAINE ${ }^{1}$}

Conocido así no por su lugar de nacimiento $^{2}$, sino por el sitio de residencia durante su vida política, James G. Blaine fue uno de los líderes más importantes del Partido Republicano en las décadas posteriores a la guerra civil, llegando a ser diputado, senador, secretario de Estado e, incluso, candidato presidencial.

Desde los 17 años se desempeñó como maestro de escuela y a los 20 contrajo matrimonio con Harriet Stanwood, originaria de Augusta, Maine, lugar a donde Blaine se trasladó cuatro años más tarde para trabajar como socio y editor del periódico republicano Kennebec Journal, evidenciando así sus inclinaciones políticas.

En 1856 asistió a la I Convención Nacional del Partido Republicano, y dos años más tarde, a la edad de 28 fue electo miembro de la Cámara de Representantes estatal. En 1860 asumió la presidencia de la Legislatura local, puesto en el que permaneció hasta su elección como representante del esta-

\footnotetext{
${ }^{1}$ Los aspectos fundamentales de la filosofía de Blaine, así como de su actuación en la vida política estadunidense, pueden ser rastreados en dos obras fundamentales del secretario de Estado, Blaine, Twenty, 1886 y Political, 1887. La mejor biografia de Blaine es la de Muzzey, James, 1934.

${ }^{2}$ Blaine nació en enero de 1830 en West Brownsville, Pensilvania.
} 
canos veían con recelo a Estados Unidos. Por lo mismo, las acciones de Blaine únicamente contribuyeron a incrementar la desconfianza.

Blaine propuso un sistema de arbitraje interamericano con el fin de aliviar las tensiones internacionales, impedir futuros conflictos y fortalecer la Doctrina Monroe. Además, esperaba incrementar las relaciones comerciales entre Estados Unidos y sus vecinos del sur. Así, en 1881 intentó llevar a cabo la idea de convocar a una conferencia interamericana para discutir el sistema de arbitraje, como un mecanismo para impedir futuros conflictos en el hemisferio occidental, invitando a las naciones independientes de América. Ello marcaría el inicio del movimiento panamericanista. ${ }^{5}$

Finalmente, Blaine fue nominado para la presidencia de Estados Unidos en 1884, únicamente para perder por un margen estrecho frente a Grover Cleveland, lo que evidenció el resurgimiento político del Partido Demócrata.

En 1889, tuvo una segunda oportunidad de aplicar sus políticas al ser nombrado secretario de Estado por el presidente Benjamin Harrison. Sin embargo, a pesar de haber encabezado la I Conferencia Panamericana, autorizada por el Congreso en 1888, ésta no tuvo los resultados que él esperaba . ${ }^{6}$

\footnotetext{
${ }^{5}$ Después de la muerte de Garfield, Blaine hubo de abandonar el Departamento de Estado. Su sucesor, Frederick T. Frelinghuysen, dio marcha atrás a la iniciativa panamericanista, la cual sería retomada por Blaine años después.

${ }^{6}$ Particularmente, la propuesta de Blaine en el sentido de que el arbitraje debía ser obligatorio en todas las controversias, excepto en aqué-
}

Blaine hubo de enfrentar además varios problemas sumamente delicados, los cuales tampoco pudo solucionar: la controversia con Gran Bretaña con respecto al derecho de las embarcaciones canadienses para cazar focas en las aguas del mar de Bering; el conflicto con Gran Bretaña y Alemania en lo concerniente a Samoa; y la tensión en las relaciones del gobierno estadunidense con Chile, después de la matanza de varios marineros estadunidenses en Valparaíso.

Con todo, y a pesar de ser un ardiente proteccionista, Blaine pudo prever la importancia de la reciprocidad para el mejoramiento de las relaciones comerciales con América Latina. Por ello, luchó para incluir una cláusula al respecto en el proyecto de ley arancelaria de McKinley, en 1890.

James G. Blaine renunció como secretario de Estado en junio de 1892 y murió en Washington, D.C., el 27 de enero de 1893.

\section{BLAINE Y EL CONFLICTO DE LÍMITES MÉXICO-GUATEMALA}

El 15 de junio de 1881, el representante del gobierno guatemalteco en Estados Unidos, Arturo Ubico, envió una nota al secretario de Estado ${ }^{7}$ solicitan-

llas en que a juicio de las naciones involucradas la soberanía se viera comprometida, fue rechazada.

${ }^{7}$ Hay que recordar que en ese momento era presidente constitucional de México el general Manuel González y fungían como secretario de Relaciones Exteriores Ignacio Mariscal y como ministro plenipotenciario en Washington Matías Romero, mientras que, en Estados Unidos, 
do la mediación estadunidense en el conflicto de límites. La respuesta de Washington no se hizo esperar. Definiendo a Estados Unidos como defensores naturales de la libertad, considerando que su intervención resultaba indispensable para alcanzar la armonía en la región y pensando también en proteger sus intereses comerciales y de seguridad nacional, Blaine ofreció sus buenos oficios para interceder ante el gobierno mexicano en favor de Guatemala.

De inmediato, manifestó el interés del presidente de Estados Unidos en la "preservación de la paz y la amistad entre las repúblicas hispanoamericanas", en beneficio de los intereses tanto de dichas repúblicas como de su propio país. Para Blaine, la política del Departamento de Estado no implicaba "constituirse en árbitro" de los destinos de las repúblicas hermanas en el continente sino que su propósito era ser el "amigo imparcial", siempre dispuesto a ofrecer su apoyo con el fin de evitar cualquier amenaza a "la paz y la prosperidad de sus vecinos". Era deber natural de Estados Unidos, en tanto que "fundador y defensor de los principios verdaderos de libertad y republicanismo como forma de gobierno para el continente americano", fortalecer por todos los medios los lazos de unión entre las repúblicas americanas. ${ }^{8}$ Por

el presidente republicano James A. Garfield había colocado al frente del Departamento de Estado a James G. Blaine y como ministro en México a Philip $\mathbf{H}$. Morgan.

${ }^{8}$ Blaine a Ubico, Washington, junio 16 , 1881, "Boundary between Mexico and Guate. mala. Message from the president of the United supuesto, el discurso de Blaine, aparentemente desinteresado, tenía como trasfondo el afán expansionista comercial del proyecto panamericanista en ciernes.

Así, el 16 de junio de 1881, Blaine, como secretario de Estado, le comunicó a su ministro en México, Philip H. Morgan, que Guatemala había solicitado formalmente del presidente de Estados Unidos sus buenos oficios para la fijación de la frontera común con México. En estas instrucciones, Blaine pedía a Morgan que informara al gobierno mexicano de la disposición de Washington a actuar como mediador. En su opinión, la mediación no tendría por objeto defender las reclamaciones de una u otra parte, ni pretendía influir en los destinos de los pueblos en conflicto.

Blaine afirmaba que su país, como "protector natural de los derechos y la integridad nacional de los gobiernos republicanos", a los cuales lo unían tanto los lazos históricos como los intereses materiales, tenía la obligación moral de responder a la petición guatemalteca. Pero, en función de un mejor entendimiento, él desearía que la solicitud viniera también de parte de México. ${ }^{10}$

States, transmitting a communication from the secretary of State relative to the boundaries between Mexico and Guatemala", Washington, 6 de mayo de 1884, 48 Congreso, 1a. sesión, House Executive Document, núm. 154, en Congressional Masterfile (en adelante $\mathrm{CM}$ ), microficha 2207 , p. 21.

9 Sensabaugh, "American", 1940, pp. 6-10.

${ }^{10}$ Blaine a Morgan, Washington, 16 de junio de 1881, "Boundary", en CM, microficha 2207 , p. 25. 


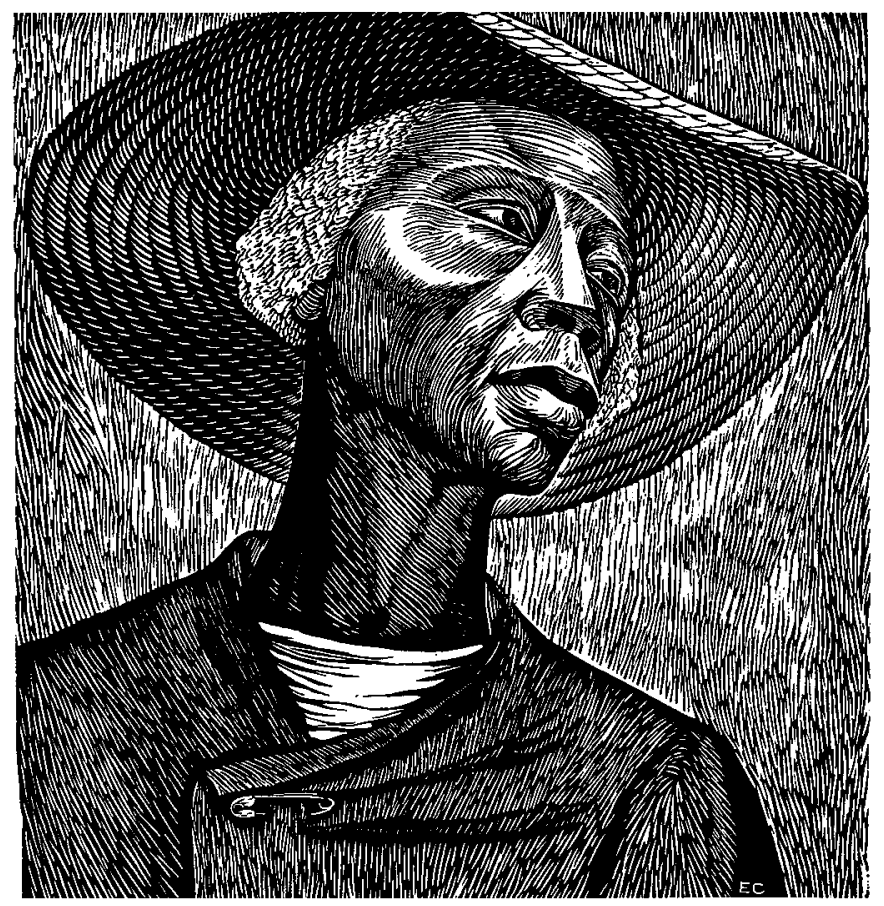

Desde su punto de vista, Estados Unidos tenía el deber moral de ejercer su influencia para preservar la integridad territorial de las repúblicas hermanas del continente frente a cualquier agresión, ya fuera que proviniera del exterior o de cualquier otro país americano. Por ello, su política exterior debía encaminarse a "evitar cualquier movimiento entre estados vecinos que pudiera destruir el equilibrio de poder entre ellos" y, por supuesto, que pusiera en riesgo la hegemonía estadunidense en la región. Un aspecto de la estrategia de Washington para asegurar la paz interna y evitar cualquier intervención externa, era que sus vecinos se convirtieran en "países prósperos con gobiernos fuertes". Y éste, afirmaba Blaine, era su deseo tanto para México como para las naciones centroamericanas. ${ }^{11}$

Así pues, debido a que el Departamento de Estado consideraba que la preservación de la paz era esencial para una política de alianzas en función de la autodefensa, ${ }^{12}$ el gobierno de Estados Unidos optó por proteger a la parte más débil, en este caso Guatemala, ya que existía el peligro de que los demás países del istmo se involucraran

${ }^{11}$ Blaine a Morgan, Washington, 21 de junio de 1881, en ibid., p. 27.

${ }^{12}$ Ibid., p. 28. 


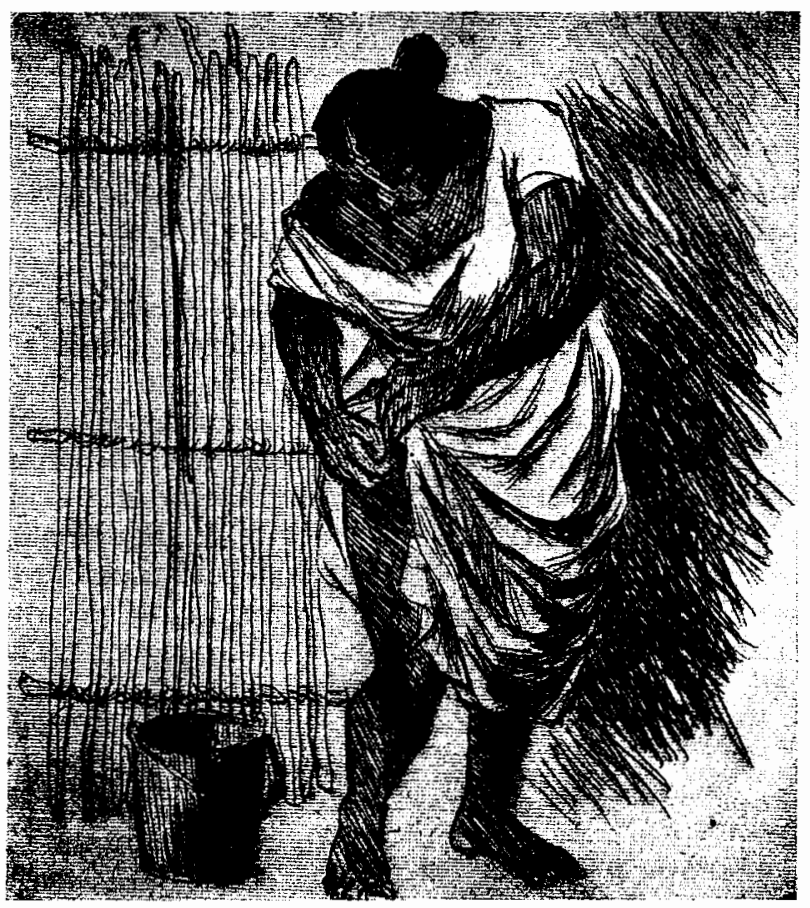

y México adquiriera una posición de fuerza regional que podría poner en riesgo la hegemonía estadunidese en el continente. $^{13}$

Por ello, en las instrucciones de Blaine a Morgan se le pedía que convenciera al gobierno mexicano de que el conflicto debía resolverse por la vía diplomática. Asimismo, tendría que advertirle que, en caso de que ésta fallara, sería necesario recurrir a la mediación. También se le sugería dejar sentado que las relaciones de México con Estados Unidos se verían fortalecidas, si su política hacia sus vecinos centroame-

${ }^{13}$ Lockey, "James", 1958, vol. 7, p. 276. ricanos era de "consideración, paz y amistad", y no de conquista. ${ }^{14}$

A pesar de que México rechazó los buenos oficios de Estados Unidos y no obstante la advertencia de Morgan, éste recibió el 28 de noviembre nuevas instrucciones de Blaine para que hiciera saber al gobierno mexicano que si se rehusaba a admitir el principio de arbitraje amistoso para resolver las diferencias internacionales en este continente, el Departamento de Estado consideraría su actitud como una

${ }^{14}$ Blaine a Morgan, Washington, 21 de junio de 1881, "Boundary" en CM, microficha 2207, p. 29. 
demostración hostil hacia Guatemala, ${ }^{15}$ contraria a las relaciones amistosas entre los gobiernos mexicano y norteamericano y como una "injuria a los intereses más nobles de todas las repúblicas del continente". ${ }^{16}$

Sin embargo, después del atentado que costó la vida al presidente James A. Garfield (1881), la posición de Blaine en el Departamento de Estado empezó a ser cuestionada. ${ }^{17}$ El vicepresidente, Chester A. Arthur, asumió la primera magistratura y, de inmediato, nombró secretario de Estado a Frederick T. Frelinghuysen. ${ }^{18}$. Frelinghuysen dio marcha atrás a todas las iniciativas de Blaine y, para empezar, no insistió demasiado ni en los buenos oficios ni en

${ }^{15}$ Lafeber, Inevitable, 1993, p. 33.

${ }^{16}$ Blaine a Morgan, Washington, 28 de noviembre de 1881, "Boundary" en CM, microficha 2207, p. 66.

${ }^{17}$ Es importante recordar que Garfield había llegado a la presidencia como candidato de compromiso del Partido Republicano. Las figuras fuertes dentro de éste, Ulysses Grant y James G. Blaine, pertenecían a tendencias políticas opuestas por lo que, con el fin de evitar una posible escisión, se eligió a un elemento "más neutral". La unidad partidaria tuvo como base la fórmula James A. Garfield-Chester A. Arthur, el primero más cercano a Blaine y el segundo identificado con el grupo de Grant. Véase Pletcher, Awkward, 1962.

${ }_{18}$ Ambos, dentro del partido republicano, formaban parte del grupo político conocido como los stalwarts, que se caracterizaba por el abuso del poder y las prácticas de excesiva corrupción. Frente a ellos, la fracción de los reformadores o balf-breeds, a la cual pertenecían tanto Blaine como Garfield, había desatado una severa crítica a las formas de corrupción en la relación política-negocios privados y habían pedido limitar la influencia de los grandes capitales en la primera. Brown, "Frederick", 1958, vol. 8 , p. 5 . el arbitraje para resolver las dificultades entre las dos repúblicas hermanas. ${ }^{19}$

\section{BLAINE Y LA CAMPAÑa DE UNIÓN CENTROAMERICANA}

El caudillo liberal guatemalteco, Justo Rufino Barrios, además de propiciar y favorecer la entrada del capital extranjero a Guatemala en condiciones de sobra favorables, recurrentemente ofreció al gobierno de Washington la cooperación de Guatemala para la construcción del canal interoceánico a través de su propio territorio o, en su caso, vía Nicaragua. Incluso, en 1879 , llegó a ofrecer en venta a Estados Unidos las islas del golfo de Honduras, de importancia estratégica para la defensa del canal transístmico.

No obstante, el entonces secretario de Estado estadunidense, William Evarts, mostró total indiferencia ante la propuesta. Sólo el ministro de Estados Unidos en Centroamérica, Cornelius A. Logan, evidenció cierto interés, sobre todo por el peligro que significaría que dicha proposición se hiciera a Inglaterra o a Alemania. ${ }^{20}$

$\mathrm{El}$ asunto no pasó a mayores pero, al año siguiente, Barrios ofreció a Logan crear la Federación Centroamericana -en la cual estarían incluidos los países del istmo, excepto Costa Rica-y favorecer a cualquier compañía estadunidense que deseara construir el canal a través de Nicaragua.

Arturo Ubico fue enviado a Washington con la finalidad de pedir protec-

\footnotetext{
${ }^{19}$ Véase Lafeber, New, 1965, pp. 46-53.

${ }^{20}$ Rippy, “Unión”, 1940, p. 16.
} 
ción y ofrecer la cooperación de Guatemala para la construcción del paso transístmico. Sin embargo, el presidente Rutherford Hayes rechazó la petición, debido a que Estados Unidos deseaban tener el predominio absoluto y no deseaban compartir el control del canal con un caudillo como Barrios. ${ }^{21}$ Además, el gobierno estadunidense estaba dispuesto a apoyar el movimiento de unificación de los países de América Central, siempre y cuando éste no se realizara por la fuerza de las armas, sino de común acuerdo. Barrios insistió de nueva cuenta en 1884, manifestando su deseo de que el canal se construyera a través de Guatemala, pero esta vez tampoco pudo lograr nada. ${ }^{22}$

Todo ello lo había ofrecido Barrios a cambio del apoyo y la protección del gobierno estadunidense para lograr el tan ansiado objetivo de volver a reunir a los cinco países centroamericanos en una sola entidad política. De aquí que las acciones del presidente guatemalteco, encaminadas a forjar la unidad de los países del área fueran en aumento, hasta culminar el 28 de febrero de 1885 , fecha en que emitiría una declaración unilateral de creación de la Unión Centroamericana, de la cual se autonombraba comandante militar supremo. Barrios esperaba la inmediata adhesión de Honduras y El Salvador y, con ella, la alineación por parte de Nicaragua y Costa Rica, aunque como último recurso también contemplaba la posibilidad de ejercer la fuerza militar para cum-

21 Ibid., p. 17.

22 Ibid., p. 18. plir con su objetivo. Sólo Honduras se adhirió, al tiempo que El Salvador se alió con Costa Rica y Nicaragua para darse apoyo militar mutuo en contra de Guatemala.

Fl conflicto armado no se hizo esperar. El 30 de marzo se iniciaron los combates entre Guatemala y El Salvador, pero pronto la guerra llevó a Barrios a la muerte, con lo cual, el movimiento unificador quedó prácticamente liquidado.

Pero, ¿cuál había sido la postura de Blaine frente a la idea de la posible unión de los países del istmo, al iniciar la década de los ochenta? En su opinión, Estados Unidos debería buscar, ante todo, "fortalecer la unión natural de las repúblicas del continente", como defensa frente a las influencias externas contrarias a las formas de gobierno de las naciones hispanoamericanas. ${ }^{23}$ Para él, cualquier elemento que lesionara la armonía entre los países hermanos del istmo debía ser combatido pues, de no hacerlo, tendría efectos desastrosos tanto en su desarrollo como en la posibilidad de garantizar una convivencia pacífica en la región. ${ }^{24}$

De aquí que el gobierno estadunidense estuviera

especialmente ansioso de promover esta gran política para ver a las repúblicas de América Central más unidas de lo que han estado en el pasado en la protección de sus intereses comunes, los cuales son, en sus relaciones futu-

${ }^{23}$ Blaine a Morgan, Washington, 16 de junio de 1881 , "Boundary" en $\mathrm{CM}$, microficha 2207 , p. 26.

${ }^{24}$ Ibid. 
ras, idénticos en principio a aquellos de México y de Estados Unidos. ${ }^{25}$

Además, Blaine veía con buenos ojos el afán unionista de Barrios, pues pensaba que la prosperidad y la fortaleza de los países centroamericanos evitarían la intervención de cualquier potencia extranjera. $^{26}$

[...] en lo que se refiere a la unión de las repúblicas centroamericanas bajo un gobierno federal, Estados Unidos estaba dispuesto a reconocer que ningún otro asunto apela más fuertemente a su comprensión ni más decididamente a su juicio; ni es ésta una nueva política. $^{27}$

Sin embargo, una de las preocupaciones fundamentales del gobierno mexicano y, en particular, de su ministro de Relaciones Exteriores, Ignacio Mariscal, era el asunto de la posible unión de Centroamérica encabezada por Guatemala. Dado que el secretario consideraba a Barrios como enemigo de México, su afán unionista le parecía francamente peligroso.

México, agregaba Mariscal, deseaba cooperar en el proceso de formación de la Unión Centroamericana, siempre y cuando ésta no fuera dirigida por el presidente Barrios, llegando a desafiarlo con la idea de aceptar la unión en América Central, siempre y cuando el líder guatemalteco no estuviera a la cabeza. Por ello, la perspectiva de que el caudillo liberal de Guatemala se convirtiera en el jefe máximo de Cen-

\footnotetext{
${ }^{25}$ Ibid.

${ }^{26}$ Ibid., 28 de noviembre de 1881, p. 65.

${ }^{27}$ Ibid.
}

troamérica, contando con el aval de Estados Unidos, le parecía a Mariscal terriblemente grave. ${ }^{28}$

Blaine y el Tratado Clayton-Bulwer

Durante su primera gestión como secretario de Estado, Blaine buscó también modificar el Tratado Clayton-Bulwer de 1850 , en el que se establecía que Estados Unidos y Gran Bretaña compartirían el control de cualquier canal a través del istmo centroamericano. Blaine intentó alcanzar un acuerdo para que pudiera construirse un canal que estuviera enteramente bajo el control de Estados Unidos, pero no lo consiguió. ${ }^{29}$

Debido al inminente inicio de la construcción del paso interoceánico en Panamá, a cargo de Fernando de Lesseps, ${ }^{30}$ se desató el rumor de que las potencias europeas consideraban necesaria una garantía conjunta acerca de la neutralidad del futuro canal. Por ello, en sus instrucciones del 24 de junio de 1881 al ministro estadunidense en Londres, James Russell Lowell, Blaine resucitó la discusión sobre el control exclusivo del futuro canal transístmico. En su opinión, la garantía de neutralidad había sido ampliamente prevista en el Tratado de 1846 entre Estados Unidos y la República de Nueva Granada, por lo que no era necesa-

\footnotetext{
${ }^{28}$ Morgan a Blaine, México, 11 de agosto de 1881 , en ibid. p. 44.

${ }^{29}$ Esto se lograría en 1901 con la firma del Tratado Hay-Pauncefote.

${ }^{30}$ Este proyecto a la postre no se lievaría a cabo.
} 
rio insistir en ello y mucho menos se requería que algún otro país lo suscribiera. $^{31}$

El secretario de Relaciones Exteriores de la Gran Bretaña. Lord Granville, respondió cuatro meses después con una breve nota, en la cual, dejaba asentado que la posición de Estados Unidos y la Gran Bretaña con respecto al canal se encontraba establecida en el Tratado Clayton-Bulwer, firmado en abril de 1850 .

En su artículo primero, ambos países pactaron que ninguno obtendría el control exclusivo del canal por la ruta de Nicaragua; en su artículo tercero, se comprometían a proteger tanto a las personas como a las propiedades de las partes involucradas en la construcción del paso; y, en su artículo octavo, se acordaba extender lo estipulado en el Tratado a las rutas de Tehuantepec y Panamá. Sin embargo, dado que sobre este último artículo no se habían hecho precisiones específicas, Blaine consideraría que los derechos y privilegios de Estados Unidos determinados en el acuerdo previo con Colombia permanecían intactos. ${ }^{32}$ Por ello, planteó la urgencia de que el Tratado Clayton-Bulwer fuera modificado, con el fin de lograr el propósito fundamental de la administración Garfield: la construcción de un canal interoceánico bajo el control estadunidense. ${ }^{33}$ En su opinión, la situación

${ }^{31}$ Lockey, "James", 1958, vol. 7, p. 292.

32 Ibid., pp. 292-293.

${ }^{33}$ Especialmente, si el canal se construía por la ruta de Nicaragua, el Tratado debía ser modificado, ibid., p. 293. internacional prevaleciente en 1850 se había transformado de manera sustancial y, por tanto, el gobierno estadunidense debía modificar su postura de acuerdo al nuevo escenario mundial. 30 años después de la firma del Tratado Clayton-Bulwer, ya nada era igual.

Blaine envió entonces un despacho a Lowell, el 19 de noviembre de 1881 , con el fin de obtener el consentimiento británico para la modificación de dicho Tratado. En él, se sugerían las modificaciones básicas que debían hacerse al texto original.

Primero, cancelar cualquier parte en la cual se prohibiera a Estados Unidos fortificar el canal y retener el control político junto con el gobierno del país en el que se construyera. Segundo, mantener vigente el compromiso de que ninguno de los dos países podría adquirir territorio en el istmo centroamericano. Sin embargo, debía quedar claro que la adquisición de las estaciones navales y militares necesarias para la protección del canal, cedidas voluntariamente a Estados Unidos por los gobiernos centroamericanos, no sería considerada como una violación a esta disposición. Tercero, Estados Unidos estaba de acuerdo en mantener la posibilidad de establecer un puerto libre en ambas entradas del canal, siempre y cuando la Gran Bretaña lo aceptara también. Cuarto, dado que la cláusula en que los dos gobiernos habian acordado elaborar algunas condiciones para la creación de un protectorado conjunto sobre el paso transístmico, ya fuera un ferrocarril o un canal, no había sido precisada por nin- 


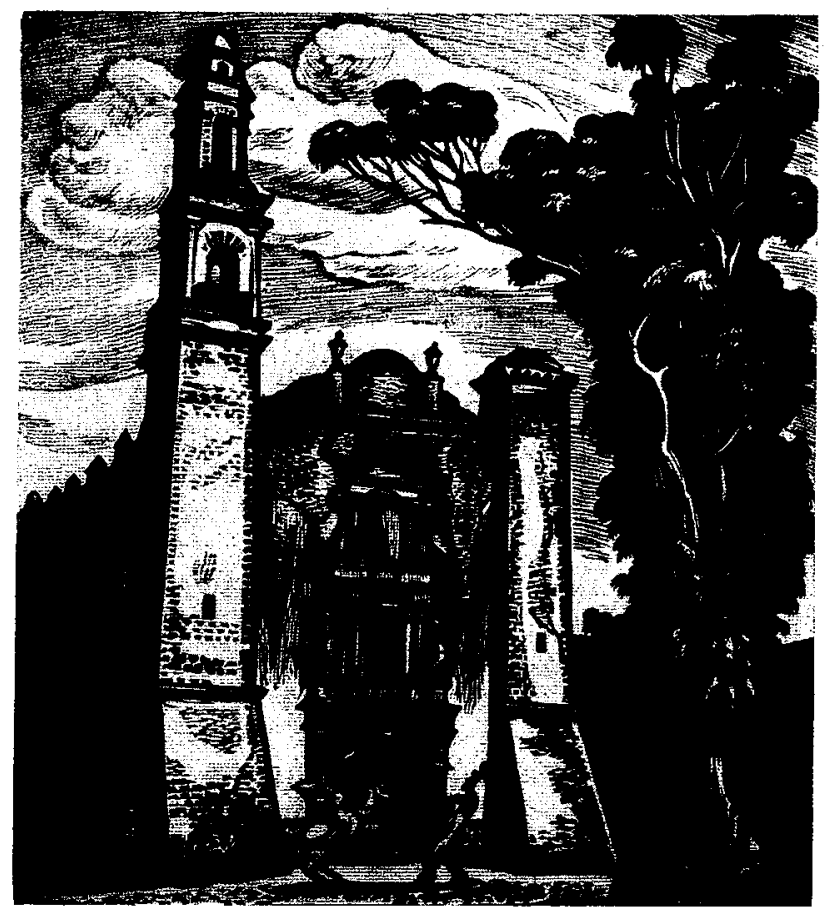

guna de las partes involucradas, ésta debía ser eliminada. ${ }^{34}$

Pero, una vez más, la respuesta de Lord Granville fue tardía. Dos extensos despachos firmados por el ministro británico fueron recibidos en el Departamento de Estado hasta enero de 1882. Consecuentemente, el encar-

\footnotetext{
${ }^{34}$ Incluso se hace referencia a la construcción de un ferrocarril en Panamá por parte de ciudadanos estadunidenses en años anteriores y al interés de realizar una empresa similar en Tehuantepec, Blaine a Lowell; Washington, 19 de noviembre de 1881, "Message from the president of the United States transmitting, in response to Senate resolution of December 12, 1881 , a report from the secretary of State, touch-
}

gado de dar continuidad a la propuesta estadunidense fue el sucesor de Blaine, Frederick T. Frelinghuysen, quien de manera excepcional no dio marcha atrás a la iniciativa de su antecesor. En este caso, Frelinghuysen iría mucho más lejos y propondría la abrogación del Tratado Clayton-Bulwer.

ing the proposed modification of the Clayton Bulwer Treaty of April 19, 1850, between the United States and Great Britain", Washington, 15 de diciembre de 1881, 47 Congress, 1a. sesión, Senate Executive Document, núm.16, en The Family papers of James G. Blaine, The Library of Congress, Manuscript Division, micropelícula 16822 , rollo 16 , p. 6 . 


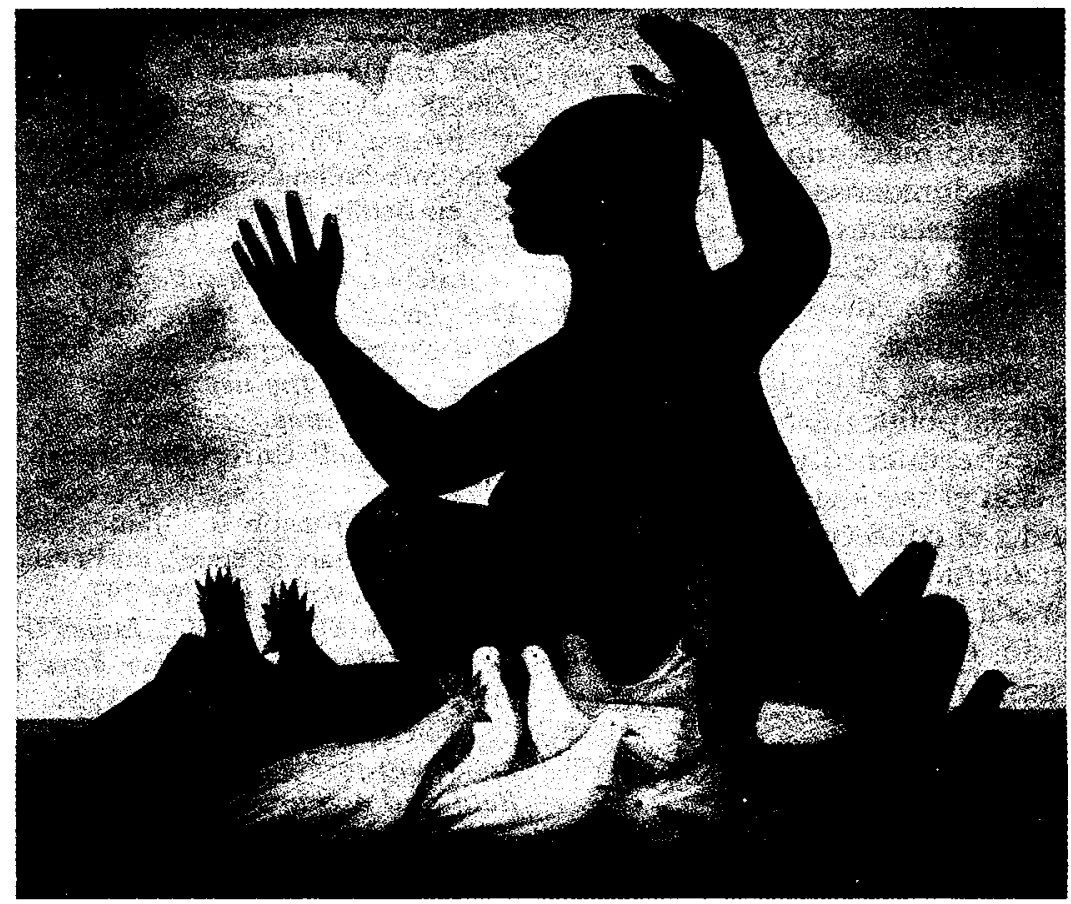

\section{CONClusiones}

La primera y breve gestión de James G. Blaine en el Departamento de Estado estadunidense fue bastante polémica. Sus iniciativas causaron amplio revuelo, tanto dentro de Estados Unidos como fuera de ellos, particularmente en los países de América Latina.

Es claro que en tan poco tiempo y con las fuertes presiones del grupo opositor dentro del Partido Republicano, la posición de Blaine se vio bastante comprometida. En la prensa estadunidense las críticas fueron constantes y evidenciaron el peso del grupo de Grant en la política interna y externa de Estados Unidos.
Sin embargo, es innegable que el interés estratégico de la administración Garfield en Centroamérica estuvo más que bien representado por la figura de Blaine. Muestra de ello fue su idea de modificar el Tratado Clayton-Bulwer con el fin de lograr el control del futuro canal interoceánico. Además, lo anterior se vio complementado por la preocupación específica del secretario de Estado en el sentido de garantizar la expansión comercial de su país en América Latina.

De aquí que su política exterior hacia Centroamérica, relativa tanto al conflicto de límites mexicano-guatemalteco como al problema de la Unión Centroamericana, estuviera permeada 
por su incipiente interés en desarrollar el proyecto panamericanista. Esto traería como consecuencia el rechazo del gobierno mexicano, temeroso del avance estadunidense en la región, así como los constantes pedidos de ayuda del gobierno de Guatemala, ingenuamente confiado en las bondades de la Doctrina Monroe.

No obstante, al inicio de los años ochenta, la política exterior estadunidense experimentó un giro importante. Con el asesinato del presidente Garfield y el consecuente relevo en el Departamento de Estado, se dio marcha atrás a los proyectos previos concluyendo, de manera abrupta, la primera gestión de Blaine de Maine.

\section{BiBLIOGRAFÍA}

-Bemis, Samuel Flagg, The american secretaries of state and their diplomacy, $\mathrm{Pa}-$ geant Book Company, Nueva York , 1958, 15 vols.

-Blaine, James G., Political discussions: legislative, diplomatic and popular, The Henry Bill Publishing Company, Connecticut, 1887.
, Twenty years in Congress: from Lincoln to Garfield, The Henry Bill Publishing Co., Connecticut, 1886, 2 vols.

-Brown, Philip Marshall, "Frederick Theodore Frelinghuysen, secretary of State", en Bemis, American, 1958, vol. 8, pp. 3-43.

-Lafeber, Walter, Inevitable revolutions. The United States in Central America, W.W. Norton Company, Nueva York, 1993. , The new empire. An interpretation of american expansion, 18601898, Cornell University, Nueva York, 1965.

-Lockey, Joseph B., "James Gillespie Blaine, secretary of State", en Bemis, American, 1958, vol. 7, pp. 264-297.

-Muzzey, David Saville, James G. Blaine, a political Idol of other days, Dodd, Meade and Co., Nueva York, 1934.

-Pletcher, David, The awkward years. American foreign relations under Gar. field and Artbur, University of Missouri Press, Columbia, 1962.

-Rippy, J. Fred, "La Unión de Centroamérica, el canal por Nicaragua y. Justo Rufino Barrios", Hispanic American Historical Review, núm. 2, vol. Xx, 1940, pp. 16-19.

-Sensabaugh, León. F., "American interest in the mexican-guatemalan boundary dispute", Birmingham-Soutbern College Bulletin, núm. 4, vol. 33, 1940, pp. 3-28. 